\title{
O Homem dos Ratos, Schreber e Kafka: Destinos Possíveis para a Hostilidade
}

The Rat Man, Schreber And Kafka: Possible Vicissitudes To Hostility

El Hombre De Los Ratones, Schreber Y Kafka: Destinos Posibles Para La Hostilidad

Sissi Vigil Castiel, Débora Farinati, Liege Horst Didonet, Maria Lucia Fortes Moreira, Roberta Araujo Monteiro, Cláudia Rocha,

Daniela Trois Feijó, Juliana Martins Costa \& Luciana Lopez Silva

Sigmund Freud Associação Psicanalítica
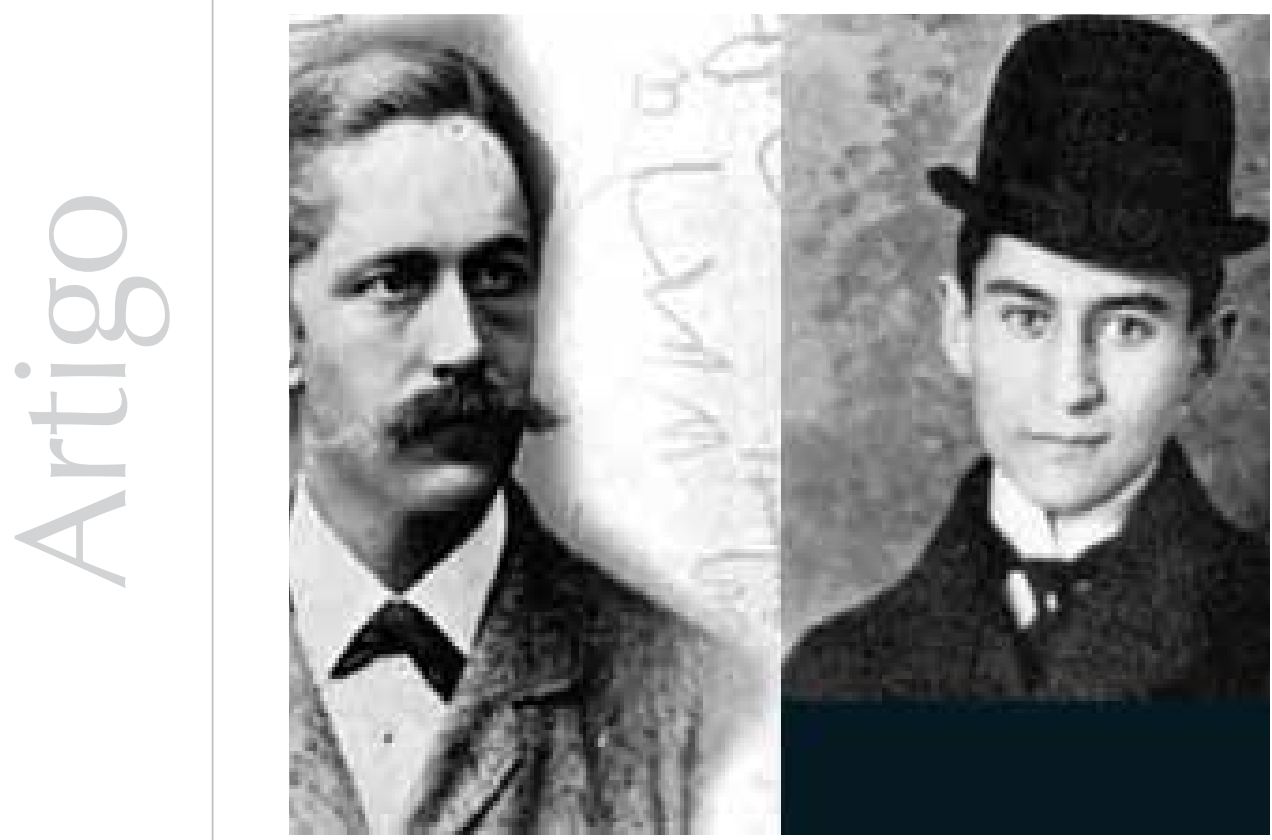
...."Da vez

primeira em que

me assassinaram

Perdi um

jeito de sorrir que

eu tinha...

Depois,

de cada vez que me mataram, Foram

levando qualquer coisa minha"...

Mario Quintana, Soneto XVII

Resumo: A clínica psicanalítica impõe a observação por vezes muito presente em determinados quadros, das tendências hostis que aparecem de forma manifesta ou fantasiada. Partindo dessa constatação e sustentado na releitura dos textos freudianos, este trabalho propõe uma reflexão sobre as tendências agressivas e suas implicações na clínica da neurose obsessiva e da paranoia, já que entendemos que a intensidade da hostilidade nessas patologias se coloca, muitas vezes, como um impasse para o tratamento. Os quadros clínicos serão exemplificados por meio do caso do Homem dos Ratos e da história de Schreber. Posteriormente, passaremos a discutir dois textos de Kafka, a fim de indicar uma saída para a elaboração da hostilidade no sentido de simbolizar e de sublimar as tendências agressivas.

Palavras-chave: Transtorno obsessivo compulsivo. Hostilidade. Sublimação. Psicanálise. Psicopatologia. Mecanismos de defesa.

Abstract: The psychoanalytical practice demands the observation of acted or fantasized hostile tendencies which are very common in certain cases. We believe that the intensity of hostility has an increase in cases like obsessive neurosis and paranoia and often become an impediment to treatment. Considering such matters and based on Freud's texts, this paper proposes a reflection on the aggressive tendencies and their implications in the treatment of obsessive neurosis and paranoia. The clinical frames will be exemplified by The Rat Man and the history of Schreber. Subsequently we will discuss two texts of Kafka, to indicate an answer to the elaboration of hostility towards symbolization and sublimation of the aggressive tendencies. Keywords: Obsessive compulsive disorder. Hostility. Sublimation. Psychoanalysis. Psychopathology. Defense mechanism.

Resumen: La clínica psicoanalítica impone la observación, algunas veces muy presente en determinados cuadros, de las tendencias hostiles que aparecen de forma manifiesta o fantaseada. Partiendo de esa constatación y sostenido en la relectura de los textos freudianos, este trabajo propone una reflexión sobre las inclinaciones agresivas y sus implicaciones en la clínica de la neurosis obsesiva y de la paranoia, ya que entendemos que la intensidad de la hostilidad en esas patologías se coloca, muchas veces, como un impasse para el tratamiento. Los cuadros clínicos serán ejemplarizados por medio del caso del Hombre de los Ratones y de la historia de Schreber. Posteriormente, pasaremos a discutir dos textos de Kafka, con el fin de indicar una salida para la elaboración de la hostilidad en el sentido de simbolizar y de sublimar las inclinaciones agresivas.

Palabras clave: Trastorno obsesivo compulsivo. Hostilidad. Sublimación. Psicoanálisis. Psicopatología. Mecanismos de defesa.

A clínica psicanalítica impõe a observação, por vezes muito presente em determinados quadros, das tendências hostis que aparecem de forma manifesta ou fantasiada. Isso se faz presente, de modo especial, na neurose obsessiva e na paranoia. A hostilidade se explicita no tratamento e impõe ao psicanalista a questão de como ela pode ser elaborada dada a sua intensidade. Dito de outro modo, entendemos que a intensidade da hostilidade nessas patologias se coloca, muitas vezes, como um impasse para o tratamento.

A agressividade, segundo Laplanche e Pontalis (2004), é a tendência que se atualiza em comportamentos reais ou fantasmáticos, visando a prejudicar ou a destruir outrem. A agressão se expressa por diversos modos além da ação motora. Colocamos em destaque a questão fantasmática presente nas tendências hostis, ou seja, a agressividade pode existir como tendência, não só em caráter de ato. Isso leva a pensar no papel que as tendências agressivas têm na construção do aparelho psíquico, o que implica dizer que a agressividade é uma tensão correlata à estrutura narcísica do sujeito. Efetivamente, a psicanálise reconhece um lugar para as tendências agressivas na constituição do psiquismo, ainda que Freud, por vezes, pensasse que isso se tenha dado tardiamente. 
Nas Novas Conferências Introdutórias sobre Psicanálise (1932/1989, p.129), por exemplo, ele se pergunta: "Por que necessitamos de tempo tão longo para nos decidirmos a reconhecer uma pulsão agressiva? Por que é que hesitamos em utilizar para a teoria fatos que eram evidentes e familiares a qualquer pessoa?" Esse comentário de Freud referese à ideia de que a postulação da segunda tópica delimita um lugar específico para a agressividade como um substrato pulsional único que caracterizaria a pulsão de morte. No entanto, evidências teóricas anteriores demonstram uma preocupação de Freud com o tema desde muito cedo, começando com a observação das tendências hostis que fazem parte do tratamento analítico. Isso se explicita em Dora (Freud, 1905a/1989), quando Freud afirma que a hostilidade deve ser despertada e utilizada pela análise ao ser tornada consciente. A hostilidade faria parte do que ele denominou, mais tarde, transferência negativa.

Nos Três Ensaios sobre a Teoria da Sexualidade (1905b/1989). Freud afirma que as tendências agressivas apareciam junto à sexualidade; portanto, nesse momento, os fenômenos da hostilidade não foram tratados a partir de uma pulsão específica, talvez, por isso, o comentário de Freud nas Novas Conferências Introdutórias sobre Psicanálise (1932/1989).

Na verdade, a hipótese de uma pulsão agressiva autônoma foi emitida por Adler em 1908, mas foi recusada por Freud. Mesmo que a autonomia pulsional da agressividade em relação à sexualidade só tenha sido especificada por ele a partir da viragem de vinte, não se pode dizer que as formulações feitas anteriormente a esse período sejam destituídas de importância. Pelo contrário, todo o tema dos destinos pulsionais, como formas de se defender da hostilidade, representam possibilidades férteis para uma metapsicologia da agressividade, bem como para a elaboração das tendências hostis na análise quando integrados com os elementos da segunda tópica.

Para o objetivo deste trabalho, faremos um percurso pelos textos teóricos freudianos, para depois abordar o modo como as tendências agressivas aparecem na clínica, através da neurose obsessiva e da paranoia. Os quadros clínicos serão exemplificados através do Homem dos Ratos e da história de Schreber. Posteriormente, passaremos a dois textos de Kafka, a fim de indicar uma saída para a elaboração da hostilidade no sentido da simbolização. Pensamos que nessas patologias exista uma impossibilidade de desligamento do objeto paterno devido à intensidade da hostilidade presente de parte a parte, o que leva o psicanalista a indagar: como é possível a fusão da agressividade com a sexualidade nesses casos? Do ponto de vista da direção da cura, é necessária a elaboração dessas tendências. $\mathrm{O}$ trabalho analítico se defronta com a volta contra si mesmo e a transformação no contrário como destinos pulsionais, particularmente utilizados por esses pacientes, o que muitas vezes representa um impasse no que diz respeito à direção da cura, dada a impossibildade de simbolização dos impulsos hostis a partir desses destinos. Dentro desse contexto, interessa-nos abordar de que forma a simbolização das tendências agressivas como sublimação da pulsão estaria relacionada à direção da cura como uma alternativa para a elaboração da hostilidade. Em função dessa hipótese de trabalho, abordamos os casos clínicos da paranoia e da neurose obsessiva e, por outro lado, os textos de Kafka.

\section{A agressividade em Freud}

Foi em função das manifestações hostis e agressivas que, necessariamente, incidiam durante o tratamento analítico, que Freud descobriu a resistência. Isso, por si só, já nos permite dimensionar a centralidade e a importância que a temática da agressividade 
tem no campo psicanalítico, participando diretamente das condições que promovem, viabilizam e sustentam a experiência analítica. A experiência clínica da agressividade na transferência permitiu a Freud o desenvolvimento de outros conceitos e ideias, como, por exemplo, a noção de ambivalência, que foi definida como coexistência, no mesmo plano, de tendências, de atitudes e de sentimentos opostos, por excelência, o amor e o ódio (Laplanche \& Pontalis, 2004); de igual modo, o complexo de Édipo, que, desde a Interpretação dos Sonhos (Freud, 1900/1989) é concebido como uma forma de apreender o problema relativo à conjunção de desejos amorosos e hostis. Também na descrição do caso Dora (1905/1989), percebe-se amplamente a articulação entre as constelações amorosas e hostis do complexo de Édipo. Ao mesmo tempo, vê-se a participação da agressividade na transferência estabelecida pela paciente com relação a Freud, o que leva à interrupção da análise.

No que diz respeito a uma metapsicologia da agressividade e seu desenvolvimento no sujeito, em um primeiro momento, Freud não a definiu em termos de uma pulsão específica, pois ele entendia que isso levaria a beneficiar um tipo específico de pulsão em detrimento de outro, tal como atesta seu comentário no Historial do Pequeno Hans sobre a postulação de uma pulsão agressiva por Adler:

Não posso convencer-me a aceitar a existência de uma pulsão agressiva especial ao lado das pulsões familiares de autoconservação e sexuais, e de qualidade igual à destas. Parece-me que Adler promoveu erradamente a uma pulsão especial e autosubsistente, o que é, na realidade, um atributo universal e indispensável de todas as pulsões - seu caráter pulsional premente, o que poderia ser descrito como a sua capacidade para iniciar movimento. Nada restaria, então, das outras pulsões, a não ser a sua relação com um objetivo, pois a sua relação com os meios de alcançar esse objetivo teria sido retirada deles pela 'pulsão agressiva'. Apesar de toda a incerteza e obscuridade de nossa teoria das pulsões, eu preferiria, no momento, aderir ao ponto de vista usual, que deixa a cada pulsão o seu próprio poder de se tornar agressiva... (1909 a/1989, pp. 145-146)

Freud se recusa a aceitar a existência de uma pulsão agressiva independente e autônoma, pois, no seu entender, cada pulsão tem o poder de se tornar agressiva. Essa mesma linha de pensamento se encontra em sua contribuição ao tema da hostilidade em 1905, nos Três Ensaios sobre a Sexualidade, quando fala na pulsão de dominação. Esta se situa na origem da crueldade infantil, e, em princípio, não teria por alvo o sofrimento alheio, mas simplesmente não o levaria em conta. Isso quer dizer que provocar dor em alguém não está entre os objetivos pulsionais da criança, e sim, que o ímpeto de dominação pode implicar a supressão do outro que se coloca como obstáculo para a dominação visada sobre algo. Freud situa a origem dessa pulsão na organização sádico-anal do desenvolvimento da libido.

O texto As Pulsões e suas Vicissitudes representa a culminância do pensamento freudiano sobre a agressividade no contexto da primeira tópica, e constitui um artigo de importância capital para a compreensão desta. No que diz respeito aos destinos pulsionais, Freud trata da transformação no contrário e da volta contra si mesmo como maneira específica de se defender de tendências pulsionais, como a agressividade, por exemplo. O primeiro desses destinos pode-se perceber em dois processos diferentes, a mudança da atividade para a passividade e a mudança do conteúdo. Já a volta contra si mesmo se dá no campo do objeto da pulsão. Esses dois processos ocorrem na transformação do sadismo em masoquismo. 
Freud situa tanto a volta contra si mesmo como a transformação no contrário como formações narcisistas, afirmando:

Se levarmos em conta a fase do sadismo preliminar e narcisista que construímos, estaremos aproximando-nos de uma compreensão mais geral - a saber, que as vicissitudes pulsionais, que consistem na volta contra si mesmo e a transformação no contrário, se acham na dependência da organização narcisista do ego e trazem o cunho dessa fase. Correspondem talvez às tentativas de defesa que, em fases mais elevadas do desenvolvimento do ego, são efetuadas por outros meios (1915/1989,

p.153)

A afirmação de Freud coloca em destaque a ideia de que as vicissitudes pulsionais da volta contra si mesmo e da transformação no contrário são maneiras específicas de lidar com o ódio, como o sadismo e o masoquismo. Em outras palavras, o ódio não é fusionado com a sexualidade; nesses destinos, ele é tratado narcisicamente, é transformado em amor ou voltado para dentro do próprio sujeito. Por isso mesmo, esses desenvolvimentos teóricos possibilitamnos pensar que a patologia consiste na manutenção desses modos de defesa com relação à hostilidade em detrimento do recalcamento e da sublimação, descritas por ele, na afirmativa acima, como tentativas mais elevadas de defesa. Nesse sentido, poder-se-ia pensar que Freud entende que a sublimação e o recalcamento são formas mais elaboradas de lidar com as tendências agressivas do que a volta contra si mesmo e a transformação no contrário. Justamente essa postulação de Freud põe em destaque a vinculação desses dois últimos destinos pulsionais com a organização narcisista, aspecto que não estaria presente na sublimação, tal como ele afirma no caso Scherber, quando diz que a sublimação é um progressivo afastamento do narcisismo. Essas postulações de Freud nesses dois textos são o que nos possibilita pensar que a sublimação das tendências agressivas teria alguma relação com a direção da cura, aspecto esse que será retomado ao final do trabalho e que só indicamos aqui a propósito de uma de nossas hipóteses de trabalho.

Já na vigência da segunda dualidade pulsional, a agressividade tem um lugar mais destacado. É a parte da pulsão de morte posta a serviço dos propósitos de Eros, voltada para fora com o auxílio da musculatura, que Freud chama pulsão agressiva. Isso ocorreria da seguinte maneira: a parte da pulsão voltada para fora seria o sadismo propriamente dito; a outra parte mantém-se no organismo, onde está ligada libidinalmente pelo auxílio da excitação sexual, o que caracteriza o masoquismo originário. Chamamos a atenção para a postulação de Freud, que é clara quanto ao que ele chama de agressividade e sua diferença para os fenômenos da destrutividade, presentes na mudez da pulsão de morte que aparecem nas condutas de atuação, por exemplo. Com isso, quer salientar-se a diferença entre a destrutividade muda, característica da pulsão de morte, e a agressividade presente em sua relação com o desenvolvimento da libido. Nessas situações, a agressividade apareceria fusionada com a libido em maior ou menor quantidade, fazendo parte de estruturas neuróticas tais como a neurose obsessiva, por exemplo, nas quais a fantasmatização está em questão. Para a finalidade deste trabalho, iremos centrar-nos nas questões relativas às tendências fantasmáticas e manifestas de hostilidade presentes na neurose obsessiva e na paranoia, portanto, nos quadros clínicos que se relacionam muito mais com a problemática da agressividade e de sexualidade do que com o mortífero em seu estado mudo.

Em O Ego e o Id, Freud (1923/1989), a partir da hipótese da dualidade pulsional entre Eros e a pulsão de morte, afirma que as duas classes de pulsão se unem e se fundem, de forma que o impulso destrutivo pode ser neutralizado, sendo desviado para o mundo externo através 
do aparelho muscular. Dessa forma, as duas classes de pulsão se unem e funcionam combinadamente. A libido constitui um fator de ligação, de fusão, enquanto a agressividade, um fator de desfusão. A partir da ideia da fusão pulsional, a desfusão é uma consequência necessária. Quanto maior for o predomínio da agressividade, mais a fusão pulsional tende a desfazer-se. Inversamente, quanto mais a libido prevalecer, mais se realizará a fusão. Nesse sentido, a essência de uma regressão da libido, da fase genital à fase anal-sádica, origina-se pela desfusão pulsional, enquanto o progresso da fase anal para a genital tem como condição um acréscimo de componentes eróticos.

Nesse sentido, o componente sádico da pulsão sexual seria o exemplo de uma fusão pulsional útil, e o sadismo, que se tornou independente como perversão, seria uma desfusão. Para fins de descarga, a pulsão de destruição é colocada a serviço de Eros. A regressão da libido reside em uma desfusão pulsional, enquanto o avanço para uma fase posterior seria um acréscimo de componentes eróticos. A ambivalência é o melhor exemplo, para Freud, de uma desfusão ou de uma fusão que não se realizou.

Para Freud, todo impulso consiste na fusão das duas categorias de pulsões que ocorre em variadas proporções. Os impulsos eróticos introduziriam a multiplicidade dos fins sexuais, enquanto os outros apenas admitiriam atenuações em sua tendência uniforme. No entanto, ambos os grupos pulsionais têm o mesmo poder e enfrentam-se no mesmo campo, gerando os comportamentos e os tipos de relações de objeto. Assim, a postulação da pulsão de morte e a ideia da fusão-desfusão pulsional permitem pensar sobre o funcionamento combinado dos dois tipos de pulsão e qual a parte respectiva e o modo de associação dos dois grandes grupos pulsionais.
Entendemos que, do ponto de vista de uma metapsicologia da agressividade, a conceituação da fusão e da desfusão pulsional a partir da segunda teoria das pulsões, bem como os destinos pulsionais da transformação no contrário e da volta contra si mesmo relativos à primeira teoria das pulsões são conceitos indispensáveis. A desfusão pulsional, por exemplo, aparece com força na neurose obsessiva e na paranoia. Com efeito, a análise dessas patologias permite ver a intensidade da agressividade presente, o que caracterizaria a desfusão pulsional. Interessa, do ponto de vista deste trabalho, investigar os impasses que se colocam para a elaboração desses impulsos que consistiriam a fusão da pulsão com a sexualidade. Dentro desse contexto, na patologia, os destinos da volta contra si mesmo e a transformação no contrário são prioritários, porque há uma desfusão pulsional que impede o recalcamento e a sublimação, pois não há a simbolização da agressividade.

Além disso, em O Ego e o ld, Freud se pergunta como se explicaria a transformação do amor em ódio. Afirma o autor que existiria no psiquismo uma energia deslocável e neutra em si própria que poderia ser acrescentada a um impulso erótico ou destrutivo, tendo assim aumentada a sua catexia total. A hipótese de Freud é bastante complexa, o que torna difícil segui-la. No entanto, é possível analisá-la com vagar. Se a energia neutra é acrescentada aos impulsos eróticos, não parece haver dúvida, pois ela é então empregada a serviço do princípio do prazer para facilitar a descarga e neutralizar bloqueios, segundo Freud. Entendemos que, nesse caso, a tendência será a busca da satisfação pulsional pela ativação das representações inconscientes, o que poderá ser barrado pelo recalcamento; aí vemos um circuito pulsional em andamento. Assim, no caso de a energia neutra incrementar os impulsos eróticos, o princípio do prazer está em funcionamento. $\mathrm{E}$, no caso de a energia ser acrescentada aos impulsos agressivos? Freud não responde a essa questão. Como hipótese, 
podemos levantar dois aspectos: por que razão mais energia seria acrescentada aos impulsos agressivos? A outra questão diz respeito às consequências desse acréscimo. Quanto à segunda questão, podemos supor que, quando um montante de energia a mais é acrescentada aos impulsos agressivos, ocasiona a desfusão pulsional e a ulterior regressão. Quanto à primeira questão, entendemos que existe um reforço de fora para que isso aconteça: a agressividade paterna ou a identificação com a agressividade paterna são o motivo para o incremento dos impulsos hostis. Nesse sentido, Lacan afirma: "(...) Um genitor severo intimida pela simples presença, e basta que seja brandida a imagem do Punidor para que a criança a forme. Ela tem repercussões mais amplas do que qualquer sevícia" (1998, p.107). Efetivamente, percebemos que, na patologia, a intensidade da hostilidade paterna presente como tendência na neurose obsessiva e na paranoia poderia consistir nesse acréscimo de energia aos impulsos hostis de que falam Freud e Lacan. Dessa forma, o sujeito ficaria capturado nas tendências agressivas. Isso justificaria o porquê da utilização prioritária dos destinos pulsionais da transformação no contrário e da volta contra si mesmo. Por outro lado, o incremento das tendências agressivas impede a fusão e acarreta a desfusão pulsional, tal como afirma Freud em O Ego e o ld, como descrevemos acima. A consequência da desfusão pulsional e da utilização da volta contra si mesmo e da transformação no contrário é a permanência do sujeito na organização narcisista, como Freud observa em Pulsões e seus Destinos, citado anteriormente. Por isso tudo, nessas patologias, é difícil a elaboração das tendências agressivas.

Por outro lado, em $O$ Ego e o Id, Freud (1923/1989) aborda a transformação da agressividade como implicação da dissolução edípica. Os impulsos agressivos do complexo de Édipo são integrados através da identificação e da sublimação nas diversas atividades sociais, profissionais, artísticas e esportivas. Essa transformação da agressividade levaria em conta a sublimação, na medida em que ela perderia sua correlação com o narcisismo, pois a castração implica a saída do narcisismo, como se pode ver no terceiro ensaio de Sobre o Narcisismo: uma Introdução (1914/1989). A agressividade deixa de ser satisfeita através do corpo, no caso do sadismo e do masoquismo, e passa, então, a ser simbolizada, dada a sua fusão com a sexualidade.

No que diz respeito a uma metapsicologia da agressividade, temos dois caminhos: o da simbolização e da sublimação e o da captura do sujeito na volta contra si mesmo e transformação no contrário. Para falar desses destinos, passamos aos casos clínicos e a Kafka.

\section{O Homem dos Ratos}

Em outubro de 1907, Sigmund Freud inicia a análise de Paul (Ernst Lanzer), um homem que se tornou célebre por ter aberto a Freud a possibilidade de elaborar uma construção teórica sólida acerca da neurose obsessiva. De acordo com Mezan (1998), o grande problema colocado pela neurose obsessiva e que surge em função do Homem dos Ratos diz respeito ao que se faz com o ódio. Pensamos que o destino dado à hostilidade marcará de forma contundente as possibilidades e as impossibilidades de satisfação de um sujeito.

Ernst Lanzer (1878-1914) nasceu em Viena, em uma família judia, sendo o quarto filho de uma prole de sete. Em $1^{\circ}$ de outubro de 1907, com 29 anos, Ernst procura Freud com um quadro grave de neurose obsessiva. Afirma Freud :

Os aspectos principais de seu distúrbio eram medos de que algo pudesse acontecer 
a duas pessoas de quem ele gostava muito: o pai e uma dama a quem muito admirava. Estava consciente, também, de impulsos compulsivos, tais como cortar a garganta com uma lâmina (1909/1989, p.163)

Esse temor, núcleo de toda a conflitiva apresentada por Ernst a Freud, decorria da ambivalência em relação aos sentimentos que nutria por esses que constituíam os objetos centrais do drama e da trama de sua história, ou seja, o pai e a dama. No centro do agravamento de sua neurose obsessiva, estava uma fantasia com ratos, da qual derivou o nome pelo qual esse caso clínico ficara conhecido, a saber: depois de ouvir, nas manobras militares de que participava, uma cruel tortura relacionada a ratos contada por um hostil capitão, Ernst passou a imaginar o castigo sendo infligido a duas pessoas, a dama, que lhe era cara, e a seu pai. A partir desse fato, desenvolveu-se uma série de ações de Ernst a fim de proteger o pai e a dama de tal tortura.

Sua história de vida foi marcada por um despertar precoce da sexualidade, sendo esse fato relatado a Freud como de muita relevância em seu desenvolvimento. Dá como exemplo um episódio, tendo ele na ocasião entre quatro e cinco anos, no qual recebera da governanta a liberação para entrar debaixo de sua saia e tocá-la em seus genitais e na parte inferior de seu corpo, com a exigência de que ele não contasse isso a ninguém. Desde então, ele passou a ter uma "curiosidade ardente e atormentadora de ver o corpo feminino" (Freud, 1909/1989, p.14). Relata que, desde os seis anos, "sofria de ereções" (Freud, 1909/1989, p. 166), e associa essa sexualidade precoce às ideias que vieram a atormentá-lo, afirmando que, já nessa época, tinha a ideia mórbida de que seus pais conheciam seus pensamentos. Ao mesmo tempo em que percebia seu forte desejo de ver nuas determinadas moças, um sentimento estranho de que algo aconteceria se pensasse em tais desejos o acometia, por exemplo: o pai deveria morrer.

O pai, figura central na história, era um homem de excelentes qualidades, embora pudesse ser, ocasionalmente, impetuoso e violento. Pai e filho, na realidade, haviam vivido como bons amigos, à exceção de um único aspecto: o pai assumira para o filho expressiva oposição à sua vida erótica. Do sentimento de que o pai constituía um obstáculo à satisfação de sua sexualidade, derivou sua hostilidade, que se expressaria pelo temor de que algo pudesse acontecer ao pai, mesmo após a sua morte. A passagem que relatamos a seguir demonstra como Ernst foi estabelecendo as conexões entre seus desejos eróticos e a ideia de que o pai a eles se opunha. Quando ele tinha por volta de três, quatro anos de idade, apanhara do pai por ter mordido alguém, provavelmente sua babá. Como reação a essa ação violenta do pai, Ernst, enfurecido, proferiu xingamentos enquanto apanhava, porém, "como não conhecia impropérios, chamou-o de todos os nomes de objetos comuns que lhe vinham à cabeça e gritou: 'Sua lâmpada! Sua toalha! Seu prato! E assim por diante'" (Freud, 1909/1989, p.52).

Posteriormente, Freud arrisca estabelecer uma ligação entre a má conduta que seria a masturbação e a repreensão (surra) impetrada pelo pai como uma censura a esse ato. Diante do ataque de fúria de Ernst, o pai, transtornado, interrompe a surra e exclama: "O menino ou vai ser um grande homem, ou um grande criminoso!" (1909/1989, p.52). Essa cena, de acordo com Ernst, ficara marcada permanentemente tanto em si mesmo quanto no pai, pois conta que, desde esse dia, ele jamais tornou a surrá-lo, por ter percebido mudança em seu caráter. Freud diz, sobre o ocorrido:

A partir daquela época, tornou-se um covarde, por medo da violência de sua 
própria raiva. Aliás, por toda sua vida, teve um medo terrível de pancadas, e costumava agachar-se e esconder-se, cheio de terror e indignação, quando um de seus irmãos ou irmãs era espancado (1909/1989, p.208)

O pai, ao mesmo tempo amado por Ernst, passa a constituir objeto de sua ira, ira essa inadmissível em sua consciência pela culpa que the imputava e que encontrou expressão em seus pensamentos de que algo pudesse acontecer ao pai.

Diversas experiências acabaram por reforçar a ideia mágica de que seus pensamentos se davam a conhecer aos pais, ficando ele convencido da onipotência de seu amor e de seu ódio, o que o compeliu a superestimar os efeitos de sua hostilidade contra o mundo externo. O ódio, de acordo com Freud, precisa necessariamente ter uma fonte, e descobri-la resultava em um grande problema para Ernst. Diz Freud: "Podemos considerar o recalcamento de seu ódio infantil contra o pai como o evento que colocou todo o seu modo de vida subseqüente sob domínio da neurose" (1909/1989, p. 239). Entendemos que, quando Freud se referia ao recalcamento do ódio, estaria colocando em questão a impossibilidade de que um ódio intenso fosse integrado aos componentes amorosos, permanecendo desfusionado da libido.

Ernst adoeceu na idade de vinte anos, aproximadamente, ao se deparar com o conflito entre o desejo paterno de que ele se casasse com uma mulher de sua escolha e o desejo de se casar com a dama a quem ele amava há tanto tempo. Os sentimentos para com o pai, assim como os que nutria pela dama, eram carregados de amor e ódio. Acrescentamos, além disso, que, nesse conflito, reatualiza-se a ideia infantil de que o pai era quem impedia a satisfação de seus desejos eróticos.
Os conflitos de sentimentos no Homem dos Ratos amalgamavam-se; o ódio à dama estava ligado ao afeiçoamento ao pai, assim como o ódio ao pai ligava-se inevitavelmente ao seu amor pela dama. Sobre isso, Freud afirma: "Sabemos que o amor incipiente com freqüência é percebido como o próprio ódio, e que o amor, se lhe é negada satisfação, pode, com facilidade, ser parcialmente convertido em ódio". Em Ernst, o amor não conseguiu suplantar o ódio, apenas baniu-o para o inconsciente através da formação reativa, e lá, protegido de ser removido pelas ações da consciência, persistiu, cresceu e infiltrouse em sua vida, produzindo um amplo espectro de manifestações sintomáticas.

\section{Schreber}

Em 1911, Freud publicou o trabalho Notas Psicanalíticas sobre um Relato Autobiográfico de um Caso de Paranóia (1911/1989), fruto do estudo detalhado do livro de memórias escrito por Daniel Paul Schreber (1842-1911), jurista renomado e presidente da Corte de Apelação da Saxônia. Este apresentou sinais de distúrbios mentais depois de ter sido derrotado na eleição em que disputava o cargo de candidato do partido conservador (Roudinesco \& Plon, 1998). De acordo com Carone (1995), em um artigo irônico de um jornal local, a matéria intitulada Quem conhece esse tal Dr. Schreber? evidenciou o anonimato de Schreber, em oposição aos méritos de seus antepassados e à celebridade de seu pai. Era o ano 1884, Schreber estava com 42 anos, e foi hospitalizado sob os cuidados do reconhecido Dr. Flechsig, com diagnóstico de hipocondria grave, tendo permanecido internado por seis meses. Após a alta, viveu um período de oito anos que considerou feliz, embora ofuscado pelas frustrações da esperança de ter filhos. Em 1893, Schreber foi nomeado presidente da Corte de Apelação de Dresden, o que representava o ponto máximo de sua 
carreira. Sentia-se honrado, mas também sobrecarregado por seus subordinados serem mais velhos e experientes do que ele. Antes da posse, teve um sonho de que a antiga doença nervosa havia voltado, e também um devaneio de que seria bom ser uma mulher no ato sexual. Em seguida, um novo colapso mental surgiu, acompanhado por insônia, sensibilidade a ruídos e angústia intensa, ideias de perseguição e morte iminente, o que acarretou um uma nova internação na clínica universitária para doenças nervosas de Lepzig (Carone, 1995).

Sete anos depois, ainda internado, Schreber foi interditado, ocasião na qual escreveu suas Memórias de um Doente dos Nervos (1903/1995), publicado em 1903. Em suas memórias, Schreber apresenta o sistema delirante no qual estabelecia uma significativa relação com Deus, tendo, inclusive, uma comunicação particular com ele pela língua fundamental, e achava que o fim do mundo estava próximo, sendo ele o único sobrevivente. Além disso, entendia que Deus the confiara a missão salvadora de gerar uma nova raça, para qual deveria se transmutar em mulher (Roudinesco \& Plon, 1998).

É importante notar que a leitura do livro de Schreber, iniciado com a Carta Aberta, torna evidente o lugar de destaque ocupado por Flechsig. Este, que foi identificado como o seu grande perseguidor, o responsável pela crise entre ele e Deus, é considerado por Freud (1911/1989) como aquele que havia ocupado o lugar paterno no delírio de Schreber. Desse modo, compreende-se a relação do paciente com o seu perseguidor, já que aquele a quem ele atribui tanto poder e influência é, claramente, alguém que desempenhou papel igualmente importante na sua vida emocional.

Freud observou analogias entre os delírios paranóicos de Schreber e os grandes sistemas reformadores da natureza humana propostos por seu pai, Daniel Gottlieb Moritz Schreber (1808-1861). Dr. Schreber, médico ortopedista e pedagogo, pregava teorias educativas extremamente rígidas e moralistas, com base em práticas de higienismo, de ginástica e de ortopedia. Em seus manuais, ele propunha corrigir os defeitos da natureza humana e remediar a decadência das sociedades, criando um novo homem: espírito puro em um corpo sadio (Roudinesco \& Plon, 1998). Segundo Carone, pregava uma doutrina rígida e moralista, objetivando um controle de todos os aspectos da vida. Para ele, a retidão do espírito era fruto do aprendizado precoce de todas as formas de contenção emocional e da supressão dos chamados sentimentos imorais, entre eles, todas as manifestações da sexualidade. A partir desses entendimentos, Dr. Schreber adotou seus métodos e experimentos na educação dos filhos, sendo esse um aspecto fundamental para a compreensão da relação estabelecida entre Schreber e seu pai.

A dinâmica da paranoia proposta por Freud (1911/1989) é que uma grande intensidade de emoção é colocada em forma de poderes externos, enquanto a sua qualidade é transformada no oposto: o perseguidor odiado e temido foi, em outra época, amado e venerado, sendo essa transformação já anteriormente experimentada com outra pessoa importante na vida do sujeito. Com isso, Freud compreende que as atitudes femininas de Schreber manifestadas em relação a Flechsig levariam à proposição de uma atitude homossexual. O delírio explicita esses impulsos não aceitos que, a partir da transformação no contrário, são sentidos como ódio. Assim, configura-se a sentença: esse homem a quem eu amo, na verdade, eu odeio.

Cabe, aqui, um exame sobre o que gera o recalcamento falho desses impulsos homossexuais, deixando o sujeito restrito 
à transformação no contrário e à volta contra si mesmo. Através do caso Schreber, Freud evidencia que a impossibilidade de exteriorizar a hostilidade em relação ao pai determina que esta seja mantida voltada para dentro em forma de passividade. Essa debilidade no direcionamento da hostilidade acarreta um recalcamento igualmente frágil dos impulsos eróticos em relação ao pai referentes ao complexo de Édipo negativo. Assim, entende-se que a única maneira que Schreber teve para lidar com o pai hostil e autoritário foi ficar permanentemente submetido a ele de forma passiva. Salienta-se, ainda, que o cenário familiar de Schreber tinha uma configuração na qual só havia espaço para um homem: o pai. Isso é confirmado não só pela evolução da doença de Schreber mas também pelo suicídio do seu irmão. Com isso, percebe-se o porquê de certos episódios na sua vida terem adquirido uma magnitude que os configuraram como desencadeantes da crise paranoica: a promoção profissional, que o colocaria em uma posição de igualdade com o pai, se considerados os valores da família, sustentando a saída da condição passiva frente a ele e a impossibilidade de ter filhos, o que pode ter significado um questionamento sobre a sua própria masculinidade. Nesses momentos de crise, irrompem os delírios a fim de encobrir uma posição homossexual a ser revista. Além disso, pode-se supor que a relação com Flechsig, marcada pelo cuidado, mesmo sendo cuidados médicos, tenha adquirido um caráter tal que ativou a relação do erótico, sobre o qual Schreber não tinha um recalcamento operante capaz de suportála, o que atualizou também o impulso.

Nessa direção, examinando-se os delírios, vêse que as percepções internas são substituídas por percepções externas, e o ódio, que não pode ser sentido como próprio, é projetado no outro, justificando o seu próprio ódio sem culpa. Com relação à particularidade da hostilidade na paranoia, em uma síntese final, percebe-se em Schreber uma hostilidade que nunca pôde aparecer, nem mesmo na infância. A posição passiva homossexual de Schreber em relação ao pai destacada por Freud impede a simbolização e a fusão da agressividade, e os destinos da transformação no contrário e no retorno contra si mesmo são os que aparecem. Diante de uma hostilidade proibida, uma das possibilidades encontradas pelo sujeito, dentro da dimensão da agressividade na paranoia, é entregarse como objeto de gozo do outro em uma posição masoquista.

\section{Kafka}

A hostilidade e o destino singular a ela dado marcam a vida de qualquer ser humano. $\mathrm{Na}$ vida dos grandes autores da literatura universal, também podemos buscar um exemplo de um entrelaçamento desse tipo. Falamos de Franz Kafka. Nasceu em 1883, em Praga, na época uma capital sem muita importância do Império Austro-Húngaro, filho de uma família imigrante judia em um país onde era minoria religiosa, que se expressava em língua alemã enquanto a maioria da população falava o tcheco. A sua ascendência e a realidade que o cercava eram vividas intensamente por ele, e marcaram profundamente sua obra.

Kafka era o primeiro filho de uma prole de seis, filho de pai enérgico, autoritário, que, através de seu temperamento despótico, marcou intensa e profundamente sua personalidade. Dentro de casa, a vontade do pai era lei, sempre prevalecia, e, desde cedo, Kafka se viu isolado.

Kafka inicia a escrever em 1912, em alemão burocrático, diferentemente de seus colegas literatos, que escreviam em um alemão inventado, meio barroco, para usar as palavras de Carone (2009). Assim criou uma linguagem própria para descrever o mundo em que vivia. Ao comentar sobre essa linguagem, diz ainda Carone: "Ela é, em si mesma, absolutamente 
desinteressante. Mas ele a usou como matéria literária para descrever o mundo alienado em que vivemos, como era essa língua. Além disso, inventou um narrador que não é mais onisciente, mas insciente; ele não sabe. Como ele, também o personagem e o leitor não sabem. Todos são pegos pela alienação, mas saímos do outro lado com uma experiência concreta do que é".

Essa experiência concreta do que é, ou do que foi, encontramos na Carta ao Pai. Esse texto tornou-se obra literária após a morte de Kafka. Originalmente, tal qual o nome nos revela, foi uma carta que Kafka escreveu ao pai, como podemos inferir, em uma tentativa de comunicação.

A Carta (Kafka, 1919/1995) nos apresenta, da primeira à ultima linha, um caráter profundamente hostil e ressentido com relação ao pai. Entre 10 e 20 de novembro de 1919, aos 36 anos, cinco anos antes de morrer de tuberculose, no sanatório de Kierling, nos arredores de Viena, Kafka faz deslindar o que acabou sendo, sem dúvida, o mais intrigante acerto de contas de um ser humano, de um homem com a figura paterna, movido por uma absoluta relação de desentendimento com o pai, que se opôs a sua terceira e última fracassada tentativa de matrimônio. Essa carta jamais chegou ao destinatário, o emblemático Hermann Kafka, apesar da negociação de Franz com a irmã mais nova, Ottla, para que se fizesse portadora da remessa. A carta é atravessada, do início ao fim, pela palavra medo. Os efeitos do método educativo e da hostilidade de Hermann em um menino tão pequeno são devastadores.

Ao escrever A Carta, Kafka recorda sua relação com o pai, cujo efeito conta através de cada lembrança. Sublinhamos o seguinte trecho da Carta: "lembro vivamente um acontecimento dos primeiros anos. Talvez tu também te lembres. Uma noite eu pedia em forma plangente, incessante, que me dessem água; certamente, não era pelo fato de eu ter sede, mas em parte talvez para incomodar e em parte para divertir-me. Depois de não terem surtido efeito algumas ameaças violentas, tiraste-me da cama, levaste-me à varanda e ali me deixaste um instante, em camisola, sozinho diante da porta fechada" (Kafka, 1919/1995, p. 86).

No trecho referido acima, percebemos a predominância da hostilidade na relação entre pai e filho e o desamparo sentido então pelo filho. Com isso, não queremos dizer que não tenha havido sentimentos amorosos nessa relação, mas, aparentemente, não foram suficientes para contrabalançar a intensidade da hostilidade presente. Frente a ela, Kafka se ressente e, talvez por isso e apesar disso, escreve.

Sua obra, em que predomina a ficção realista, ao mesmo tempo esconde e denuncia a marca dessa hostilidade e desse ressentimento. É assim também na Metamorfose (Kafka, 1912/1995), na qual se descortina uma realidade absurda e profundamente vivida na passividade. O personagem principal, Gregor Samsa, transforma-se em um inseto monstruoso, e isso é vivido como um destino inelutável. Não há escolha, não há escapatória, não há nada mais a fazer do que submeter-se ao que já está dado, pois a metamorfose já havia acontecido antes de a novela iniciar. Samsa foi metamorfoseado, é um inseto, que é descrito por um outro ativo, o narrador. O personagem-inseto nem sabe estar e mover-se em seu próprio casco, torna-se a vergonha da família, escondido da sociedade e não olhado pelos olhos do pai, no seu agora abismal quarto de dormir. Destacamos o seguinte trecho da obra:

Um dos lados do seu corpo elevou-se, ele estava deitado em posição oblíqua na altura da porta; um de seus flancos ficou bastante esfolado, na porta branca ficaram manchas horríveis e em pouco estava entalado no 
vão de entrada e não conseguia mais se mover sozinho (...) foi aí que seu pai Ihe desferiu um violento golpe por trás - desta vez salvador de verdade - e ele voou, sangrando em abundância, quarto adentro. A porta ainda foi fechada com a bengala, depois, enfim, ficou tudo em silêncio (1912/1995, p.42)

Esse ser não humano em que o personagem Gregor Samsa se transformou não se reconhece no olhar do pai, não encontra alguém com quem se identificar, não tem valor, nem merece voz, lugar, nem amor. A nulidade em que se transforma Gregor é originalmente sentida pelo próprio Franz, que disse ao pai: "aquilo foi, então, um pequeno princípio, mas essa sensação de nulidade (sobre outro ponto de vista, sem dúvida, uma sensação também nobre e frutífera), que com frequência me domina, foi em grande parte provocada pela tua influência" (1912/1995, p. 86).

Com isso, não queremos dizer que Gregor Samsa represente Franz Kafka, pois o primeiro é uma criação do segundo, e aí está toda a diferença. Diferentemente do personagem, e como citado acima, Kafka vê, no próprio sentimento de nulidade, uma oportunidade para criar obra e vida. Assim como o amoroso do pai não contrabalançou o hostil, podemos pensar que toda a capacidade criativa de Kafka dá conta de uma oportunidade de criação a partir dessa hostilidade.

Ao mesmo tempo, a nulidade vivenciada a partir da hostilidade do pai para com ele e dele para com o pai levou Kafka a pensar em suicídio algumas vezes. Dessa ideação suicida nos fala Konder "embora por diversas vezes Kafka tenha encarado a hipótese de se suicidar, não chegou a aceitar tão plenamente o caminho da autodestruição" (1979, p.90). Dessa forma, a hostilidade manifesta na ideação suicida nunca se transforma em ato suicida. O hostil vivenciado em relação ao pai é redirecionado contra si mesmo, na vida, na impossibilidade de transformar seu talento de escritor em fonte de renda e de satisfação.

Apesar disso, a genialidade de sua obra fala por si. Podemos entender essa genialidade como resultado de um processo de simbolização. Em Kafka, entendemos que foi possível simbolizar parte da hostilidade vivenciada na relação com o pai, que coexiste juntamente ao destino pulsional da volta contra si mesmo. Do livro de Janouch (1971, p.196), baseado em seus registros dos tempos em que visitava Kafka em seu escritório, aprendemos a importância da amizade na vida do poeta. Kafka foi para Janouch "a mais importante e fundamental experiência da sua juventude". A relação de Kafka com Max Brod é uma das amizades mais importantes da história da literatura. Ele e Felix Weltsch foram os grandes incentivadores do escritor para que deixasse seus trabalhos serem publicados. E foi ao amigo e testemunho Brod que Kafka pediu que queimasse parte desses escritos. Em mais uma e derradeira prova de admiração e amizade, o pedido foi ignorado. E a literatura universal conheceu um de seus maiores escritores, o maior prosista de todos os tempos, nas palavras de Adorno, citado por Carone (2009). Slavutzky (2009) destaca o valor que a amizade e os vínculos fraternos tiveram na vida de Kafka no sentido de contrabalançar seus dissabores familiares.

\section{A sublimação como destino pulsional}

Para falar sobre a possibilidade de dar um destino sublimatório à hostilidade relativa à pulsão perverso-polimorfa, antes é necessário descrever o modo como se constitui a sexualidade no sujeito.

A sexualidade, em Freud (1905/1989), é definida como relativa a todas as excitações 
e atividades que levam ao prazer desde a infância, independentemente da genitalidade e das necessidades fisiológicas. Assim, Freud afirma que, desde a infância, surgem excitações e tensões no corpo que são satisfeitas por um objeto externo em um primeiro momento. Essa satisfação fica como uma marca, uma inscrição. Quando uma nova tensão semelhante surgir, a tendência será a de buscar uma satisfação análoga. Dessa forma, Freud demonstra que a sexualidade surge como uma tensão no nível do corpo, que dispara certa marca psíquica. Essa articulação entre corpo e psiquismo é o que ele chama de pulsão. Em um segundo momento, a sexualidade se torna independente do objeto externo, e a satisfação é buscada através do próprio corpo do sujeito, o que caracteriza o autoerotismo. Nesse período, a fonte e o objeto da pulsão coincidem. O autoerotismo é sucedido pelo narcisismo, quando o ego se torna o objeto da pulsão. Em todo o transcorrer da sexualidade infantil, Freud caracteriza a pulsão como perverso-polimorfa no sentido de que todas as fontes corporais estão em igualdade de condições. O fim da satisfação diretamente corporal da pulsão sexual perverso-polimorfa ocorre através do recalque, que impossibilita a realização pulsional. Com isso, a sexualidade só será satisfeita no nível do corpo, novamente, a partir da puberdade, com a genitalidade.

O recalque impõe a não satisfação das pulsões parciais, e, com isso, possibilita a transformação do narcisismo e a castração. Assim, Freud (1915/1989) coloca o recalque como um destino pulsional. As pulsões sexuais infantis não podem ser satisfeitas, e o recalque expulsa os representantes pulsionais para o inconsciente. Ainda assim, o recalque não é uma ação única, e os representantes pulsionais podem retornar através de derivados. Além disso, define outros destinos para que o sujeito possa se defender das pulsões, entre eles, a sublimação como um destino posterior ao recalque. $\mathrm{O}$ que caracteriza a sublimação é que ela trata de uma satisfação da pulsão, de uma forma substituta, e não diretamente, através do corpo. Trata-se de uma volatilização. Claro está que as formulações freudianas sobre o recalque e a sublimação vão além das posições firmadas em 1914/15, e atravessam toda a sua obra. No que diz respeito à sublimação especificamente, Freud não tem uma posição única. No entanto, para o objetivo deste trabalho, serão utilizadas as formulações desse período no sentido de se poder traçar um paralelo entre esses dois destinos pulsionais e sua relação com a sexualidade e a hostilidade.

Entende-se, então, que a formulação dos destinos pulsionais permite supor que, a partir do recalque das pulsões parciais, passa a existir uma nova possibilidade para a perversidade-polimorfa, que é a satisfação simbólica, na qual se perde a dimensão corporal. Isso constitui a sublimação da sexualidade. Nesse sentido, o que se sublima são as pulsões parciais de ver, de exibir-se, de maltratar e de ser maltratado. Sublimar essas pulsões significa que outros objetos podem ser constituídos como símbolos dos objetos originais. Entendemos que é por isso mesmo que Freud usa a palavra sublimação para definir esse processo, no sentido da evaporação, da passagem do sólido ao gasoso. Quando as pulsões parciais não podem ser satisfeitas, e, por isso, são recalcadas, depois do complexo de Édipo, existe a possibilidade de que sejam sublimadas, no sentido de que aí serão satisfeitas como uma abstração, uma evaporação. É evidente que o processo de simbolização se inicia anteriormente ao Édipo. A partir disso, pode-se observar que a sexualidade em Freud tem, além da genitalidade, uma dimensão criativa, de realizações, ou seja, é a sexualidade sublimada que viabiliza as realizações humanas no plano da cultura. No entanto, para que isso aconteça, é preciso que os objetos primários tenham sido recalcados, o que marca a 
diferença entre recalque e sublimação. Em 1914, Freud tenta diferenciar esses destinos pulsionais, especificando melhor cada um desses mecanismos; afirma que a sublimação é um mecanismo posterior ao recalque; logo, é preciso que haja recalcamento antes para poder se ter a capacidade de sublimar. Ao mesmo tempo, Freud observa que o conteúdo pulsional sublimado não é o mesmo que é recalcado, e que nem toda pulsão pode ser sublimada, pois uma parte da sexualidade deve ser satisfeita: a sexualidade genital. Por outro lado, quanto ao recalcamento secundário que se dá no fim do complexo de Édipo, os objetos primários são recalcados, abrindo portas para outros objetos, através dos quais a sexualidade irá se satisfazer no futuro. Do contrário, se não há recalque, o sujeito fica alienado em uma posição narcisista, na qual os objetos são simulacros de si mesmo.

Justamente aí, diante dessas possibilidades de destinos pulsionais no complexo de Édipo, é que vamos falar da agressividade. Uma pulsão parcial, na melhor das hipóteses, seria recalcada e/ou sublimada. No entanto, algo ocorre na paranoia e na neurose obsessiva que impossibilita esses destinos.

Em Schreber, ainda que se perceba um excesso de hostilidade no pai, o que importa, aqui, é o seu efeito no filho, na medida em que é colocada em ato, no nível do corpo. Podemos supor que isso impossibilita o recalque das pulsões parciais. Em termos de destinos pulsionais, a hostilidade vivida no real do corpo aparece como transformação no contrário, e volta-se contra si mesmo: na passividade, no masoquismo. A agressividade posta em ato não permite sua simbolização, e, dessa forma, só pode ser vivida como masoquismo.

O excesso de hostilidade faz com que não se possa recalcar o objeto para o qual a hostilidade é dirigida. Isso implica a impossibilidade da saída do narcisismo. Nesse sentido, Freud (1911/1989) afirma, na análise de Schreber, que o narcisismo é uma dessublimação. Assim, a sublimação só seria possível se o sujeito se afastasse desse modelo primário de relação com objeto paterno; do contrário, não há a possibilidade de metabolizar a agressividade.

De forma semelhante, também no Homem dos Ratos está presente o impedimento da sublimação da agressividade. Ainda que o sintoma obsessivo faça referência a uma simbolização dada à formação de substitutos, não se trata de uma realização pulsional, e sim, da simbolização como retorno do recalcado. Tal como afirma Castiel (2007), à diferença do retorno do recalcado, a sublimação contém em si uma satisfação decorrente da realização da pulsão, enquanto o retorno do recalcado é uma impossibilidade de realização pulsional. No entanto, não há dúvida de que existe uma capacidade simbólica constituída na neurose obsessiva, não observada na paranoia.

Nesse caso, a intensidade do ódio sentido para com o pai impediu o recalque do objeto paterno (que ficou para sempre como o obstáculo à concretização dos desejos eróticos do paciente), deixando-o capturado. A fim de que pudesse lidar com o ódio em relação a esse pai visto como obstáculo aos seus desejos eróticos, Ernst lançou mão de mecanismos como a dúvida e a formação reativa, assim como de destinos pulsionais, da transformação no contrário e da volta contra si mesmo.

Diferentemente desses modelos, temos em Kafka a possibilidade de simbolização da agressividade vivida na relação parental que aparece concretamente na criação literária, ainda que, em muitas situações e produções de Kafka, a agressividade diretamente dirigida ao pai fique evidente. O papel da criação literária e das amizades 
fala a favor de um processo de simbolização da agressividade, enquanto as tendências suicidas, a impossibilidade de relações amorosas como queria, o ressentimento e a impossibilidade de satisfação no trabalho falam de uma parte da agressividade que não pôde ser transformada; houve em Kafka, portanto, uma simbolização da agressividade até onde o ressentimento permitiu.

Lacan (1986) faz ver as consequências que tem um pai severo para a constituição do psiquismo do sujeito. Com efeito, os três exemplos citados dão mostra disso. Podemos dizer que a neurose obsessiva e a paranoia são impossibilidades de transformar essa condição. No entanto, diante do trágico, é necessária a criação de algo novo, uma possibilidade sublimatória que volte o olhar para o horizonte do desejo.

No que diz respeito à clínica psicanalítica, podemos dizer que a direção da cura se relaciona à transformação pulsional no sentido de um funcionamento psíquico heterogêneo, tal como afirmam diversos autores. Luis Horstein (1981), por exemplo, afirma que a clínica psicanalítica deve ter uma preocupação com a direção da cura, pois, de outra forma, preocupar-se-ia apenas com questões filosofantes. O autor entende que a direção da cura relaciona-se a uma transformação pulsional. Da mesma maneira, Joel Birman (1997) entende que a direção da cura se relaciona com a simbolização das forças pulsionais. Castiel (2007) fala da sublimação como um dos dispositivos de que dispomos na clínica para a simbolização. Entendemos que a sublimação é o destino pulsional que se relaciona à satisfação pulsional proporcionada pela simbolização das pulsões, tal como demonstramos na página anterior, e assim esse poderia ser um destino que se relacionasse à direção da cura. Com isso, não estamos afirmando que faz parte da experiência analítica uma higienização do sujeito ou que o analista tenha ideias de perfeição. Estamos tentando trabalhar os impasses causados na clínica à elaboração das tendências agressivas. Dentro desse contexto, a hostilidade constitutiva do sujeito, que aparece com especial intensidade na neurose obsessiva e na paranoia, torna-se, muitas vezes, um impasse para a experiência analítica. Com relação à cura, a transformação das tendências agressivas, que tem no corpo uma satisfação masoquista, poderia relacionar-se à abertura dos canais de sublimação a partir de sua simbolização. Esse é o papel da psicanálise: resgatar o valor das possibilidades humanas de transformação, o que constitui a lógica da esperança. 


\section{Sissi Vigil Castiel}

Psicóloga, psicanalista, doutora em Psicanálise pela Universidade Autônoma de Madri, membro pleno, Diretora de Ensino, Supervisora e Coordenadora de seminários da Sigmund Freud Associação Psicanalítica, Porto Alegre - RS- Brasil.

E-mail: scastiel@terra.com.br

\section{Débora Farinati}

Mestre em Psicologia Clínica pela PUCRS. Psicóloga, psicanalista, membro titular e diretora administrativa da Sigmund Freud Associação Psicanalítica, Porto Alegre - RS - Brasil.

E-mail: debfarinati@yahoo.com.br

\section{Liege Horst Didonet}

Psicóloga e especialista em Saúde Pública pela Universidade Federal do Rio Grande do Sul, Psicanalista em formação pela Sigmund Freud Associação Psicanalítica, Porto Alegre - RS - Brasil.

E-mail: liegedidonet@yahoo.com.br

\section{Maria Lucia Fortes Moreira}

Psicóloga e especialista em Psicoterapia de Orientação Psicanalítica pela Unisinos. Psicanalista em formação pela Sigmund Freud Associação Psicanalítica, Porto Alegre -RS - Brasil.

E-mail: mluforts@terra.com.br

\section{Roberta Araujo Monteiro}

Psicóloga e mestranda em Psicologia Clínica (Bolsista CNPq - PUCRS), Psicanalista em formação pela Sigmund Freud Associação Psicanalítica, Porto Alegre - RS - Brasil.

E-mail: roberta.monteiro@live.com

\section{Cláudia Rocha}

Psicóloga e psicanalista em formação pela Sigmund Freud Associação Psicanalítica, Porto Alegre - RS - Brasil. E-mail: rochapsico@gmail.com

\section{Daniela Trois Feijó}

Psicóloga e psicanalista em formação pela Sigmund Freud Associação Psicanalítica, Porto Alegre - RS - Brasil. E-mail: danitrois@gmail.com

\section{Juliana Martins Costa}

Psicóloga e psicanalista em formação pela Sigmund Freud Associação Psicanalítica, Porto Alegre - RS - Brasil. E-mail: julianamartinscosta@gmail.com

\section{Luciana Lopez Silva}

Psicóloga e psicanalista em formação pela Sigmund Freud Associação Psicanalítica, Porto Alegre - RS - Brasil. E-mail: lopez.lu@hotmail.com

\section{Endereço para envio de correspondência:}

Frei Henrique Trindade 430, Boa Vista, Porto Alegre - RS - Brasil. CEP: 90480140

Recebido 27/08/2010, 1a Reformulação 26/12/2011, Aprovado 17/06/2012. 


\section{Referências}

Birman, J. (1997). Estilo e modernidade em psicanálise. São Paulo: Editora 34

Carone, M. (1995). Da loucura de prestígio ao prestígio da loucura. In M. Carone (Org. e trad.). Memórias de um doente de nervos. Rio de Janeiro: Paz e Terra.

Carone, M. (2009, 19 de julho). Diante de Kafka. Folha de São Paulo, São Paulo.

Castiel, S.(2007). Sublimação: clínica e metapsicologia. São Paulo: Escuta.

Freud, S. (1989). Fragmento da análise de um caso de histeria. In Edição standard brasileira das obras psicológicas completas de Sigmund Freud. Rio de Janeiro: Imago Trabalho original publicado em 1905a).

Freud, S. (1989). Análise de uma fobia em um menino de cinco anos. In Edição standard brasileira das obras psicológicas completas de Sigmund Freud. Rio de Janeiro: Imago (Trabalho original publicado em 1909a).

Freud, S. (1989). As pulsões e suas vicissitudes. In Edição standard brasileira das obras psicológicas completas de Sigmund Freud. Rio de Janeiro: Imago (Trabalho original publicado 1915).

Freud, S. (1989). O ego e o id. In Edição standard brasileira das obras psicológicas completas de Sigmund Freud. Rio de Janeiro: Imago (Trabalho original publicado 1923).

Freud, S. (1989). Interpretação dos sonhos. In Edição standard brasileira das obras psicológicas completas de Sigmund Freud. Rio de Janeiro: Imago (Trabalho original publicado em 1900).

Freud, S. (1989). Notas psicanalíticas sobre um relato autobiográfico de um caso de paranóia (1911). In Edição standard brasileira das obras psicológicas completas de Sigmund Freud. Rio de Janeiro: Imago (Trabalho original publicado em 1911)

Freud, S. (1989). Notas sobre um caso de neurose obsessiva. In Edição standard brasileira das obras psicológicas completas de Sigmund Freud. Rio de Janeiro: Imago (Trabalho original publicado em 1909b).

Freud, S. (1989). Novas conferências introdutórias sobre psicanálise. In Edição standard brasileira das obras psicológicas completas de Sigmund Freud. Rio de Janeiro: Imago (Trabalho original publicado em 1932).

Freud, S. (1989). Sobre o narcisismo: uma introdução. In Edição standard brasileira das obras psicológicas completas de Sigmund Freud. Rio de Janeiro: Imago (Trabalho original publicado em 1914).

Freud, S. (1989). Três ensaios sobre a teoria da sexualidade. In Edição standard brasileira das obras psicológicas completas de Sigmund Freud. Rio de Janeiro: Imago (Trabalho original publicado em 1905b).

Horstein, L. (1981). Cura psicanalítica e sublimação. Porto Alegre: Artes Médicas.
Janouch, G. (1971). Conversations with Kafka (2nd. ed). New York: New Directions Publishing.

Kafka, F. (1995). Metamorfose - um artista da fome - Carta ao pai (T. Guimarães, trad.). São Paulo: Martin Claret (Trabalhos originais publicados em 1912, 1919 e 1924, respectivamente).

Konder, L. (1979). Kafka - vida e obra. Rio de Janeiro: Editora Paz e Terra.

Lacan, J. (1986). O seminário. Livro I. Os escritos técnicos de Freud. Rio de Janeiro: Jorge Zahar (Trabalho original publicado em 1979).

Lacan, J. (1998). A agressividade em psicanálise. In J. Lacan. Escritos. Rio de Janeiro: Jorge Zahar.

Laplanche, J., \& Pontalis, J. (2004). Vocabulário da psicanálise. São Paulo: Martins Fontes.

Mezan, R.(1998). Escrever a clínica. São Paulo: Casa do Psicólogo.

Roudinesco, E., \& Plon, M. (1998). Dicionário de Psicanálise. Rio de Janeiro: Editora Jorge Zahar.

Schereber, S. (1995). Memórias de um doente dos nervos. In M. Carone (Org. e trad.). Memórias de um doente dos nervos. Rio de Janeiro: Paz e Terra (Obra original publicada em 1903).

Slavutzky, A. (2009). Quem pensas tu que eu sou? São Leopoldo, RS: Unisinos. 